\title{
Os signos de consumo e a vida material
}

Clotilde Perez e Eneus Trindade

Desde a sua criação no ano de 2009, a Revista Signos do Consumo busca situar os estudos da mediação e da midiatização do consumo, bem como dos usos midiáticos que implicam o consumo/recepção das mídias, dentro do campo maior das Ciências da Comunicação, como sustenta a noção de campo científico dada por Pierre Bourdieu.

Na primeira edição da revista, os signos do consumo ganhavam mais um espaço de divulgação científica, decorrente da constatação da ampliação da semiosfera no campo do consumo. Ou seja, reino dos signos se expandiu, ocupando novos espaços que demandam novas percepções sobre os ambientes culturais.

Tal constatação levou, no segundo número da Revista, à discussão sobre as múltiplas expressões dos signos do consumo, considerando a riqueza de manifestações deste universo que demanda especial atenção da comunidade científica, no que se refere à constituição de seus significados e produções de sentidos na vida cultural.

Todavia, esses sentidos na vida cultural se dão por meio das transferências de significados que acontecem a partir do sistema produtivo das mercadorias para os significados de pertinência dos bens de consumo na vida dos indivíduos, como nos faz perceber o antropólogo Grant McCracken.

Esses processos de transferências, segundo o antropólogo americano, são mediados por um sistema comunicativo ou publicitário, que faria a conexão entre o sistema produtivo e o consumidor, construindo nos discursos de promoção e divulgação desses bens, as representações referentes aos rituais cotidianos de consumo.

Esses rituais representariam práticas de consumo sugeridas que podem ser incorporados, na perspectiva da interação simbólica das dinâmicas cotidianas, como práticas de consumo efetivas.

É inegável que o sistema publicitário tem papel fundamental nesses processos culturais de transferências de significados, midiatizados. Contudo, sabe-se que sua eficácia se dá, sobretudo, pelo fato de que as marcas das mercadorias comunicadas constroem um universo 
simbólico que passa a ser desejado pelo universo dos consumidores, criando valores que são maiores do que os valores de usos das mercadorias em si.

Isso significa dizer que as mercadorias que atendem apenas as nossas demandas cotidianas de usos estabeleceriam vínculos sígnicos materiais. Mas, quando as mercadorias são indicadoras de outros significados culturais, como status, estilo de vida, que é o que acontece na maioria das vezes, elas criam vínculos simbólicos. Como nos fez perceber Jean Baudrillard na sua clássica discussão sobre o "Sistema dos objetos", ou como nos faz entender Di Nallo em sua discussão sobre os "Meeting points" ou pontos de contatos em situações dinâmicas de consumo.

Tal fato é decorrente do processo histórico de desvalorização dos valores de uso para a supervalorização dos valores de troca e de posse dados na estetização da mercadoria (discutido primeiramente por Karl Marx e depois atualizado por Wolfgan Fritz Haug), que constituem a dimensão simbólica das mercadorias para garantir a funcionalidade da lógica da mais valia, como reflexo dos processos mercantis e financeiros do sistema capitalista, cuja base se dá nos usos e consumos do mundo material, dos objetos.

Essa história da vida material, como propôs Fernand Braudel, que também dialoga com a história do cotidiano abordada por Michel de Certeau, é constituída pela relação humana com os objetos manipuláveis, cuja função social se estabelece no contato imediato destes com o corpo e deste último na relação e no contato com o ambiente. São relações sinestésicas, em que o corpo se impõe como o principal mediador da experiência material do homem. O que, sob o ponto de vista antropológico de Mary Douglas, Baron Isherwood e Grant McCraken, ganha uma concepção estendida para a noção de "cultura da vida material".

Nesse sentido, os artigos desta terceira edição (vol. 2, n1 de 2010), convidam o leitor, a partir dos textos de seus colaboradores, a refletir e compreender aspectos dos fenômenos da mediação sígnica do consumo na vida material.

O primeiro artigo Tem leite para os mamíferos? Reflexões sobre a marca e publicidade na cadeia produtiva do leite, Profa. Dra. Maria Berenice da Costa.

Machado da FABICO/Universidade Federal do Rio Grande do Sul, discute aspectos da mediação publicitária na vida material do consumo alimentar, a partir de célebres campanhas de leite. 
O segundo texto, da Profa. Dra. Maria Lília Dias de Castro, docente da Pós-Graduação em Ciências da Comunicação da Universidade Federal de Santa Maria - RS, Em torno da autopromoção: o samba da globalização, trata da autopromoção da TV Globo e da representação da ritualização de seus programas no cotidiano dos seus telespectadores, em suas tramas intertextuais dada pelo spot televisivo da emissora.

Já o terceiro artigo Semiótica e publicidade: uma leitura dos discursos publicitários e bancários, de autoria das Professoras Me. Jane Cristina Baptista da Silva e da Dra. Rosália Maria Netto Prados do Programa de Pós-graduação em Semiótica, Tecnologias da Informação e Educação da Universidade Braz Cubas - SP, traz a discussão sobre os aspectos dos vínculos de sentidos da vida material financeira, na compreensão da oferta dos serviços pelas instituições bancárias a seus clientes na mediação publicitária de campanhas dos bancos.

O artigo seguinte, O kitsch está cult da Profa. Dra. Christina Maria Pedrazza Sêga da Universidade de Brasília, aponta para a revitalização da discussão sobre o kitsch enquanto importante artifício estético da ressignificação das mercadorias no consumo da vida material.

As professoras Dra. Maria Ângela Pavan e Dra. Josimey C. Silva, ambas da Universidade Federal do Rio Grande do Norte, com o artigo Tatuagem: cultura de massas e afirmação subjetiva incorporadas, problematizam a questão da tatuagem de produtos cuturais aplicados ao corpo, demarcando os efeitos subjetivos do consumo de produtos culturais que afetam a subjetivação dos indivíduos a ponto de levá-los a marcar os signos da Indústria Cultural em seus corpos.

E, em uma outra perspectiva, em relação aos texto anteriores, os dois artigos na sequência abordam a memória subjetiva, dada pela mediação da materialidade da publicidade.

No primeiro desses textos, a Profa. Dra. Flaílda Brito Garboggini, da Pontifícia Universidade Católica de Campinas, no seu texto Em busca de uma compreensão dos signos da propaganda do Governo Militar, discute os efeitos de tais campanhas a partir de suas memórias pessoais, o que revitaliza a interpretação de um momento histórico Brasileiro na visão de uma pesquisadora da área de publicidade e propaganda.

No segundo texto, a memória é evocada no trabalho Estampa chita: cesura e memória no descontínuo da história dos vencedores, de autoria da Mestranda em Letras da Universidade Vale do Rio Verde-MG, Emanuela Francisca Ferreira Silva. 
Em ambos os artigos, a memória se faz mediar por aspectos do consumo da vida material.

E o último artigo deste número, de autoria coletiva dos Professores do Instituto Federal de Educação, Ciência e Tecnologia de Alagoas, Me. Miquelina Cavalcante; Dra. Rossana Gaia; Me. Patrícia Lins e Me. Áurea Rapôso, aborda os Signos do design de interiores: interfaces entre uso, consumo e arte, que apresentam a discussão sobre função, estética e informação no uso do design para constituição de sentidos na vida material dos ambientes de consumo.

Por fim, são publicadas duas resenhas que fecham as discussões deste número da Revista Signos do Consumo. A primeira delas, de autoria do Prof. Dr. Eneus Trindade, da ECA/USP, refere-se à obra Tramas Publicitárias. Narrativas ilustradas de momentos marcantes da publicidade, (São Paulo: Ática, 2009), apresenta sua leitura sobre a proposta dos autores João A. Carrascoza (Professor Doutor da ECA/USP e da ESPM) e de Christiane Santarelli (Publicitária e Doutora em Comunicação pela ECA/USP), a partir da instigante reflexão sobre a Literatura e publicidade: interfaces estéticas para um conhecimento sensível sobre o mundo.

E a segunda resenha, Marcas Multissenssoriais, de autoria do Mestrando em Administração da Pontifícia Universidade Católica de São Paulo, resgata a obra de Martin Lindstrom, intitulada Brandsense: a marca multissensorial (Porto Alegre: Bookman, 2007), para discutir os efeitos sensíveis que as marcas criam para estabelecer vínculos de pertinência com a vida material dos indivíduos.

E, como tem sido feito em todas as edições da revista, damos desfecho a esta apresentação, manifestando, neste primeiro número do segundo ano da Revista Signos do Consumo, os nossos agradecimentos a todos os que nos apoiam na realização deste projeto. A revista agora se consolida buscando o seu permanente aperfeiçoamento, trazendo desafios reflexivos a cada número e já possui uma indexação no portal Univerciência (www.revistas.univerciencia.org).

Agradecemos também ao Chefe do Departamento de Relações Públicas Propaganda e Turismo da ECA/USP, Prof. Dr. Victor Aquino, pelo apoio incondicional ao projeto desta revista. A todos os colegas da ECA e da USP, de universidades do

Brasil e do exterior que aceitaram fazer parte do Conselho Científico da revista. E, principalmente, à equipe de Secretaria e produção da Revista, composta por Gabriela Ceribelli Talarico, Victor Farah Brahim, Bruno Pompeu, Fábio Alvim e Lílian Nosralla, à ARCO- Associação de Apoio à Comunicação e Artes, representada pelo Prof. Dr. Arlindo Ornelas Figueira Neto, e aos Coordenadores dos Cursos de Especialização do Departamento de Relações, Públicas, Propaganda e Turismo da ECA em: Pesquisa de Mercado em Comunicações; Marketing Político 
e Propaganda Eleitoral; Publicidade \& Mercado; Comunicação em Marketing, que patrocinaram a produção dos dois números deste ano.

Além destes, cabe ainda ressaltar que a coordenação da Revista Signos do Consumo, realizada na gestão do GESC3 - Grupo de Estudos em Semiótica, Comunicação, Cultura e Consumo CNPq/USP e PUCSP, comprometeu-se com a qualidade de seu corpo de avaliadores, o que, certamente, garantiu o êxito dos propósitos deste novo espaço de divulgação científica, e que merecem os nossos mais respeitosos reconhecimentos.

Dessa maneira, agradecemos nominalmente aos avaliadores deste número: Prof. Dr. Adolpho Queiroz (UMESP), Prof. Dr. Dennis de Oliveira (USP), Profa. Dra. Eliana Meneses de Melo (UBC), Prof. Dr. Eneus Trindade (USP), Prof. Dr. Eduardo Refkalefsky (UFRJ), Prof. Dr. Goiamérico Felício (UFG), Prof. Dr. João Anzanello Carrascoza (ESPM/USP), Prof. Dr. Leandro Batista (USP), Prof. Dr. Luciano Maluly (USP), Profa. Dra. Maria Clotilde Perez (USP), Profa. Dra. Marta Maia (UFOP), Prof. Dr. Paulo Cunha (UFPE), Prof. Dr. Paulo Nassar de Oliveira (USP), Profa. Dra. Sandra Maria Ribeiro de Souza (USP), Prof. Dr. Sérgio Bairon (USP), Prof. Dr. Vander Casaqui (ESPM), Profa. Dra. Vera Crevin (Mackenzie) e Prof. Dr. Wilton Garcia (UBC).

Por fim, agradecemos a todos os autores deste número que contribuíram com seus textos para garantir o sucesso desta revista.

Desejamos a todos uma boa leitura.

Os Organizadores. 